\title{
Topotecan vitreous and plasma levels and retinal toxicity after transcorneal intravitreal delivery in healthy albino rabbits: Alternative retinoblastoma treatment
}

\author{
Denisa Darsova a, Pavel Pochopa , Jiri Uhlik ${ }^{b}$, Eva Klapkovac, Hundie Tesfayec, Daniela Kodetovad , Jan Lestake, \\ Josef Malis', Ludek Vajner
}

\begin{abstract}
Aim. To determine intravitreal and plasma concentrations and retinal toxicity after transcorneal intravitreal injection of $1 \mu \mathrm{g}$ and $2 \mu \mathrm{g}$ of topotecan (Hycamtin).

Method. Twelve healthy albino rabbits were included in this in vivo experiment. Six anesthetized albino rabbits received a single transcorneal intravitreal injection of $1 \mu \mathrm{g}$ (group A) or $2 \mu \mathrm{g}$ (group B) of topotecan. Vitreous and blood samples were collected until $168 \mathrm{~h}$. Left eyes were treated with the same volume of saline. Plasma and vitreous levels of topotecan were determined by high-performance liquid chromatography. Area under the plasma concentration time curve (AUC) was calculated using trapezoidal rule. Clinical evidence of toxicity was classified into four grades according to anatomical structures. Electroretinograms (ERGs) were recorded.

Results. Time to maximum concentration was observed up to $2 \mathrm{~h}$ after drug injection in group A whereas up to $1 \mathrm{~h}$ in group B. Low levels of topotecan were detected in plasma in both groups and in the vitreous humor of the contralateral eye in group B. Topotecan levels (mean vitreous AUC in group A $2.55 \mu \mathrm{g} / \mathrm{mL}$.h and in group B $5.338 \mu \mathrm{g} / \mathrm{mL} . \mathrm{h}$ ) were detectable up to $6 \mathrm{~h}$ in both groups. We observed following structural changes in rabbit eyes: corneal vascularization, cataract, hemophthalmus, choroidal edema and focal retinal atrophy. Abnormal ERGs were obtained.

Conclusion. Our findings proved that transcorneal intravitreal administration of $1 \mu \mathrm{g}$ and $2 \mu \mathrm{g}$ of topotecan results in potentially cytotoxic intraocular concentrations. More studies are needed to establish the safety of topotecan for retinoblastoma in children.
\end{abstract}

Key words: intravitreal drug delivery, intravitreal seeding, periocular injection, retinoblastoma, topotecan

Received: September 29, 2011; Accepted: November 30, 2011; Available online: December 20, 2011

http://dx.doi.org/10.5507/bp.2011.068

${ }^{a}$ Department of Ophthalmology for Children and Adults, Charles University $2^{\text {nd }}$ Faculty of Medicine and Motol Hospital, Prague, Czech Republic

${ }^{b}$ Department of Histology and Embryology, Charles University $2^{\text {nd }}$ Faculty of Medicine, Prague

'Department of Clinical Biochemistry and Pathobiochemistry, Charles University $2^{\text {nd }}$ Faculty of Medicine and Motol Hospital, Prague

${ }^{d}$ Department of Pathology and Molecular Medicine, Charles University $2^{\text {nd }}$ Faculty of Medicine and Motol Hospital, Prague

${ }^{e}$ Department of Ophthalmology, Clinic of Jan Lestak, Prague

${ }^{f}$ Department of Paediatric Haematology and Oncology, $2^{\text {nd }}$ Faculty of Medicine and Motol Hospital, Prague

Corresponding author: Denisa Darsova, e-mail: denisa.darsova@centrum.cz

\section{INTRODUCTION}

Retinoblastoma represents approximately $3 \%$ of all pediatric malignancies and is the most common intraocular malignancy in children ${ }^{1,2}$. Despite the improved therapeutic indices achieved with systemic chemotherapy, complete tumor control is difficult in most children with advanced stages of retinoblastoma. The main problem with systemic chemotherapy in these cases is the recurrence of vitreous or subretinal seeds ${ }^{3,4}$. Systemically administered chemotherapeutic drugs usually fail to achieve significant concentrations in the vitreous humor because of low permeability across the blood-retinal barrier and due to the avascular vitreous humor. To reach regular therapeutic vitreous levels of anticancer drugs while maintaining low systemic toxicity, alternative strategies have been developed by a number of ophthalmic oncologists.
Currently, subconjunctival delivery is used in conjunction with systemic chemotherapy to boost the local dose of carboplatin ${ }^{5}$. However, intravitreal carboplatin concentrations reached after subconjunctival delivery are irregular ${ }^{6-8}$ and this strategy can cause serious adverse effects such as ischemic necrosis with atrophy of the optic nerve and subsequent blindness ${ }^{9,10}$.

Thus, researchers continue to investigate local delivery of potentially non-toxic drugs to improve ocular salvage. Topotecan, a specific topoisomerase I inhibitor that is capable of producing lethal damage during the course of DNA replication ${ }^{11,12}$, has shown promising antitumor activity in pediatric solid tumors and leukemia ${ }^{13-15}$. The first study to examine the pharmacological penetration of topotecan into the vitreous cavity in animals demonstrated that periocular delivery of topotecan reached potentially active levels in the vitreous humor but sys- 
temic absorption accounted for most topotecan delivery ${ }^{16}$. Rapid drop-off in vitreous concentration of chemotherapeutic agent after periocular delivery is an impediment to efficacy. Consequently, fibrin sealant was tested, to extend the duration of time of transscleral penetration of topotecan ${ }^{17}$. Subconjunctival delivery of topotecan in fibrin sealant prolonged the period of sufficient topotecan vitreous levels up to 3 weeks after treatment. However, cytotoxic effects of topotecan in fibrin sealant did not differ significantly from the effects of topotecan in aqueous vehicle and there are no reports concerning treatment after vitreous seeding. To achieve higher topotecan levels in the vitreous humor, experiments were carried out on the pharmacokinetics of this drug following intravitreal delivery. Potentially therapeutic concentrations were reached in the vitreous humor up to $48 \mathrm{~h}$ after transscleral delivery of $5 \mu \mathrm{g}$ of topotecan. This study was limited by the potential retinal toxicity that was not assessed ${ }^{18}$.

The aim of the present study was to establish the safety of transcorneal intravitreal delivery of topotecan in relation to concentration using an animal model.

\section{MATERIALS AND METHODS}

\section{In vivo experiment}

In vivo experiment was approved by the Ethics Committee for Animal Welfare of Charles University, 2nd Faculty of Medicine. The animals were anaesthetized intramuscularly with a mixture of ketamine $(50 \mathrm{mg} / \mathrm{kg}$, Narketan 10 a.u.v. inj., Vétoquinol, Lure Cedex, France) and xylazine $(5 \mathrm{mg} / \mathrm{kg}$, Rometar $2 \%$ a.u.v. inj., Spofa, Prague, Czech Republic) throughout the experiment. Twelve healthy male albino rabbits (Anlab, Prague, Czech Republic) were divided into two groups of 6 rabbits each. Group A received transcorneal intravitreal injection of $1 \mu \mathrm{g}$ of topotecan (Hycamtin, GlaxoSmithKline Beecham Plc., Brentford, United Kingdom) with a 29-gauge insulin syringe into the right eye. Group B was injected by transcorneal intravitreal injection of $2 \mu \mathrm{g}$ of topotecan with the same type of syringe. Considering retinoblastoma treatment, we used a proven approach through the limbus, anterior chamber and peripheral iris which can prevent seeding of tumor cells to the orbital tissues if used in retinoblastoma patients ${ }^{8}$. Left eyes were treated with the same volume of saline $(0.1 \mathrm{~mL})$. Before the treatment and each withdrawal, conjunctival sacks were disinfected by $3 \mathrm{~mL}$ of $1 \%$ Povidone-Iodine solution (Betadine, EGIS Pharmaceuticals Ltd., Budapest, Hungary) and anesthetized by Topical oxybuprocaine eye drops $(0.4 \%$, Benoxi gtt., Unimed Pharma, Bratislava, Slovakia).

\section{Sampling schedule}

Vitreous and blood samples were collected up to $168 \mathrm{~h}$ (at intervals of 1 h, 2 h, 6 h, 24 h, 48 h, 168 h). Only vitreous samples from left eyes were obtained at $6 \mathrm{~h}$ post injection as no measurable topotecan was found at longer times in group A. Our results were obtained from the opposite site to drug injection area to prevent withdrawal of vitreous samples with possible higher topotecan concen-

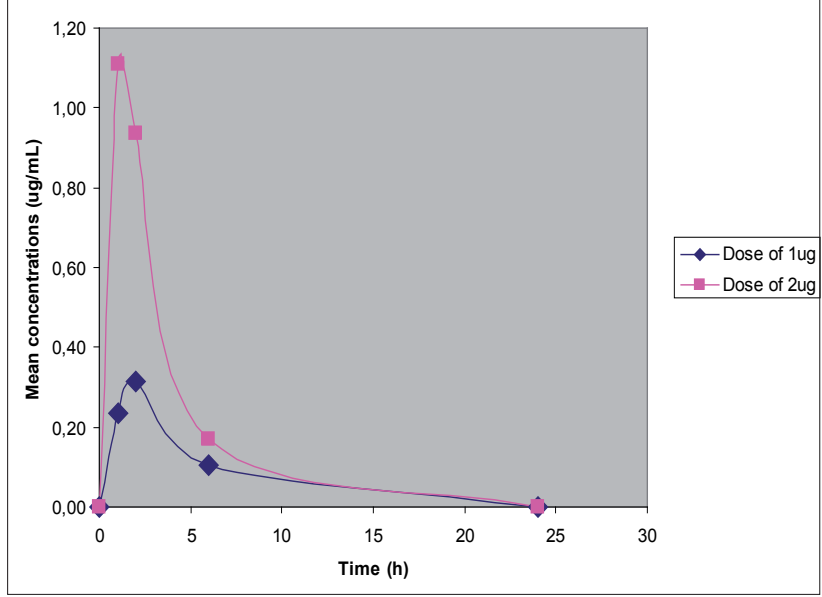

Fig. 1. Mean topotecan concentrations-versus-time profile in vitreous humor of right eyes after transcorneal intravitreal injection of $1 \mu \mathrm{g}(\downarrow)$ and after transcorneal intravitreal injection of $2 \mu \mathrm{g}(\boldsymbol{\square})$. Symbols represent individual data points and lines represent the predicted concentrations for topotecan vitreous concentrations.

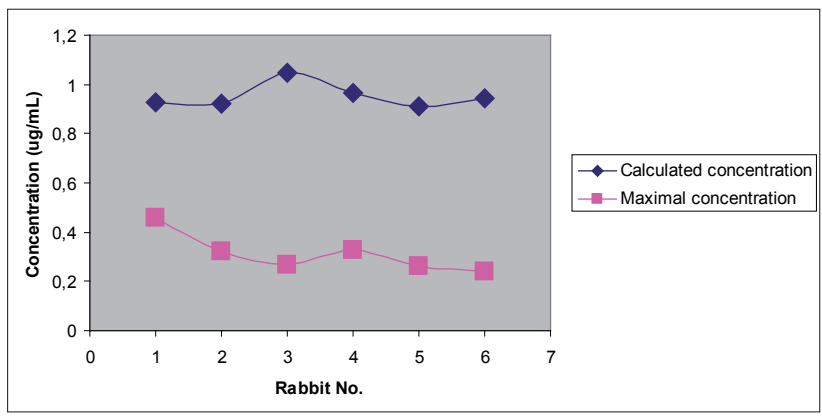

Fig. 2. Measured topotecan concentrations in rabbits versus calculated topotecan concentrations $(\mu \mathrm{g} / \mathrm{mL})$ in the vitreous according to measured globe diameter by the intravitreal application of $1 \mathrm{ug}$ of topotecan.

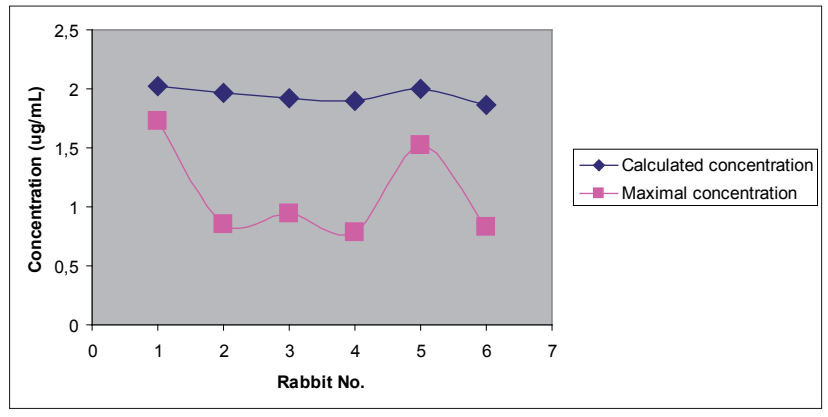

Fig. 3. Measured topotecan concentrations in rabbits versus calculated topotecan concentrations $(\mu \mathrm{g} / \mathrm{mL})$ in the vitreous according to measured globe diameter by the intravitreal application of 2 ug of topotecan.

tration. At each withdrawal, $150 \mu \mathrm{L}$ to $400 \mu \mathrm{L}$ of vitreous humour were aspirated from the vitreous chamber with a 25-gauge needle inserted transcorneally by the limbus through the anterior chamber and the base of the iris. At each sampling time, the rabbit's eyes underwent clini- 
cal examination with a fundoscopy. Blood samples were drawn from the peripheral auricular vein and placed in tubes with ammonium heparinate.

\section{Topotecan concentration measurement}

Plasma and vitreous levels of topotecan were determined by high-performance liquid chromatography (HPLC). Topotecan, kindly donated by GlaxoSmithKline, England, was used as standard using a modified HPLC method that has been described ${ }^{19}$. A volume of $100 \mu \mathrm{L}$ of sample was pipetted into a $1.5 \mathrm{~mL}$ polypropylene tube and $200 \mu \mathrm{L}$ of methanol was added for protein precipitation. The tubes were mixed for $10 \mathrm{~s}$ and centrifuged for $5 \mathrm{~min}$ at $14000 \mathrm{rpm}\left(4^{\circ} \mathrm{C}\right) .100 \mu \mathrm{L}$ of clear supernatant were transferred to the autosampler vials and $50 \mu \mathrm{L}$ were injected into the system. Detection was performed at 267 $\mathrm{nm}$, the column temperature was maintained at $25^{\circ} \mathrm{C}$. The mobile phase was prepared from $0.01 \mathrm{M}$ potassium dihydrogenphosphate adjusted to $\mathrm{pH} 3.0$ and acetonitrile $(85: 15)$. The mobile phase flow rate was $1.5 \mathrm{~mL} \cdot \mathrm{min}^{-1}$. The analysis was performed on a $150 \mathrm{~mm}$ x $4.6 \mathrm{~mm}, 5 \mu \mathrm{m}$ Inertsil ODS column. No interferences were found during the analysis. The area under the plasma concentration time curve (AUC) was calculated using a trapezoidal rule.

\section{Histological examination}

After euthanasia, performed by exsanguination from the carotid arteries, the eyes were enucleated together with eyelids and retrobulbar tissues and fixed in $10 \%$ formalin. The specimens were dehydrated by a graded series of ethanol and embedded in paraffin. Sections $(5 \mu \mathrm{m}$ in thickness) were stained with haematoxylin \& eosin and examined by an experienced pathologist.

\section{Grading of toxicity}

Clinical evidence of toxicity was classified into four grades according to the anatomical structure. Grade 1 included any signs of toxicity in the periocular orbital con- tents. Grade 2 was designed as a scleral toxicity, involving the conjunctiva, the sclera and the cornea. Remaining substructures of the rabbit's eye with clinical evidence of topotecan toxicity form grade 3 - ocular toxicity. Grade 4 - systemic toxicity - included all clinical and histological evidence of systemic topotecan toxicity in rabbits. Grades 1 and 2 were usually not considered for dose limiting toxicity. Local topotecan treatment should not be broken in these cases because of minimal effect on visual function. Any grade 3 or grade 4 were designed as dose limiting toxicity.

\section{Retinal function evaluation}

Electroretinograms (ERGs) were recorded at the beginning and at the end of the experiment in group B. Electroretinographic readings consisted of series of intensities presented under dark- and light-adapted conditions according to the ISCEV protocol. Pupillary mydriasis was induced by instillation of one drop of tropicamide $0.5 \%$ (Mydrum, Chauvin Ankerpharm GmbH). After 30 min of dark adaptation, rod ERGs were recorded simultaneously with a skin electrode and direct corneal ERG-jet contact lens electrode. The skin electrode was placed $1 \mathrm{~cm}$ behind the lower lid. A skin electrode on the forehead served as a ground. Stimulation and recording of the ERGs were performed with the RETIscan system (Roland Consult, Brandenburg, Germany).

\section{Statistical analysis}

Average values are represented as means \pm SD. t-tests for independent groups (Graph Pad Prism 5.03) were used to determine the significance of mean differences. $P<0.05$ was considered significant, $P<0.01$ was considered very significant.

Table 1. Electroretinography recorded before and after the single transcorneal intravitreal injection of $2 \mu \mathrm{g}$ of topotecan. CA a represents wave A of cone activity, CA b means wave b of cone activity, RA responds to rod activity. MSO corresponds to maximal scotopic answer. SD means standard deviation.

\begin{tabular}{|c|c|c|c|c|c|c|c|c|c|c|c|}
\hline EYE & & $\begin{array}{l}\text { CA a } \\
\text { before }\end{array}$ & $\begin{array}{l}\mathrm{CA} \text { a } \\
\text { after }\end{array}$ & $\begin{array}{l}\text { CA b } \\
\text { before }\end{array}$ & $\begin{array}{l}\mathrm{CA} \mathrm{b} \\
\text { after }\end{array}$ & $\begin{array}{c}\text { RA } \\
\text { before }\end{array}$ & $\begin{array}{l}\text { RA } \\
\text { after }\end{array}$ & $\begin{array}{l}\text { MSO a } \\
\text { before }\end{array}$ & $\begin{array}{l}\text { MSO a } \\
\text { after }\end{array}$ & $\begin{array}{l}\text { MSO b } \\
\text { before }\end{array}$ & $\begin{array}{c}\text { MSO b } \\
\text { after }\end{array}$ \\
\hline \multirow{5}{*}{ Right } & Median & 6.13 & 7.88 & 65.45 & 66.65 & 41.7 & 51.55 & 64.2 & 41.55 & 131 & 139.5 \\
\hline & Maximum & 12.3 & 12.1 & 75.6 & 87 & 56.3 & 110 & 86.9 & 93.90 & 152 & 275.0 \\
\hline & Mean & 6.70 & 6.88 & 64.68 & 62.75 & 40.9 & 52.88 & 64.98 & 50.82 & 131.5 & 153.8 \\
\hline & $\mathrm{SD}$ & 4.21 & 4.99 & 9.496 & 22.02 & 11.69 & 33.55 & 13.23 & 25.72 & 15.13 & 64.00 \\
\hline & $P$-value & \multicolumn{2}{|c|}{0.95} & \multicolumn{2}{|c|}{0.85} & \multicolumn{2}{|c|}{0.43} & \multicolumn{2}{|c|}{0.27} & \multicolumn{2}{|c|}{0.45} \\
\hline \multirow{5}{*}{ Left } & Median & 7.605 & 11.92 & 57.6 & 82.3 & 29.55 & 60.45 & 63.2 & 67.50 & 124 & 145.5 \\
\hline & Maximum & 14.80 & 389 & 83.1 & 128 & 76.5 & 194 & 90.6 & 128.0 & 151 & 292.0 \\
\hline & Mean & 7.84 & 71.8 & 57.4 & 79.82 & 38.65 & 68.54 & 65.33 & 73.52 & 122.32 & 154.4 \\
\hline & SD & 4.33 & 155.5 & 14.83 & 35.65 & 20.42 & 69.32 & 16.60 & 34.81 & 24.25 & 87.30 \\
\hline & $P$-value & \multicolumn{2}{|c|}{0.59} & \multicolumn{2}{|c|}{0.19} & \multicolumn{2}{|c|}{0.34} & \multicolumn{2}{|c|}{0.62} & \multicolumn{2}{|c|}{0.43} \\
\hline
\end{tabular}




\section{RESULTS}

\section{Topotecan concentrations}

In both groups in this experiment, the doses were sufficient for achieving the target vitreous concentrations (Fig. 1). The maximum vitreous concentration of topotecan was reached up to $2 \mathrm{~h}$ for group $\mathrm{A}$ and up to $1 \mathrm{~h}$ for group B after drug injection. After steep increase in concentrations, topotecan vitreous levels dropped fast and were under the limit of detection in $24 \mathrm{~h}$ in both groups. Mean maximum vitreous concentrations were $0.31 \mu \mathrm{g}$ / $\mathrm{mL}$ in group A and $0.94 \mu \mathrm{g} / \mathrm{mL}$ in group B. These values differed significantly $(P=0.0006)$. Conversely, there was no significant difference in mean concentrations reached between group A and group B in $6 \mathrm{~h}$ after drug injection $(P=0.0664)$. The measured maximal intravitreal concentrations of topotecan in group A and group B were approximately twice lower than the hypothesised topotecan concentrations that were calculated according to the globe diameter (Fig. 2, 3). Mean AUC in vitreous humor was $2.155 \mu \mathrm{g} / \mathrm{mL} . \mathrm{h}$ for group A and $5.338 \mu \mathrm{g} / \mathrm{mL} . \mathrm{h}$ for group $\mathrm{B}(P=0.0001)$.

In this experiment, we also measured sufficient concentrations of topotecan in plasma up to $6 \mathrm{~h}$ (Fig. 4). The plasma concentration curves have the same profile for both groups. Reached concentrations were lower in plasma than those measured in vitreous humor. In contrary to our expectations, sufficient concentrations of topotecan were obtained from left eyes at $6 \mathrm{~h}$ in group B (Fig.5).

\section{Toxicity}

Three right eyes treated with $1 \mu \mathrm{g}$ of topotecan and 4 right eyes treated with $2 \mu \mathrm{g}$ of topotecan developed choroidal edema. Additionally, we observed reduction of ganglion cells with focal retinal atrophy in 2 treated and 2 untreated eyes of group B (Fig. 6). A diminution in the size of all retinal cells and their scattering within retinal layers were seen in these eyes of group B (designed as grade 3 - dose limiting toxicity). At the end of this experiment, we noted cataractous changes in 2 treated eyes of each group. One treated eye in group B and 1 untreated eye in group A developed hemorrhage in the vitreous. All eyes of both groups presented with corneal vascularisation around the injection site. This pathologic reaction was not designed as dose limiting toxicity. Histopathological examination of the rabbits' eyes revealed lymphocytic infiltration of 4 left eyelids in group A whereas no pathologic changes were found on the right eyelids in either groups. Mean body weight change did not differ significantly between the two treated groups and all rabbits gained weight regularly throughout the experiment.

\section{Electroretinogram}

Electroretinograms displayed reductions in the darkadapted (rod-mediated) a-wave amplitudes and lightadapted (cone-mediated) b-wave amplitudes of right eyes in group B. Nevertheless, according to used statistical analysis, these findings were not significant (Table 1). Statistical analysis of ERGs revealed increase of a-wave

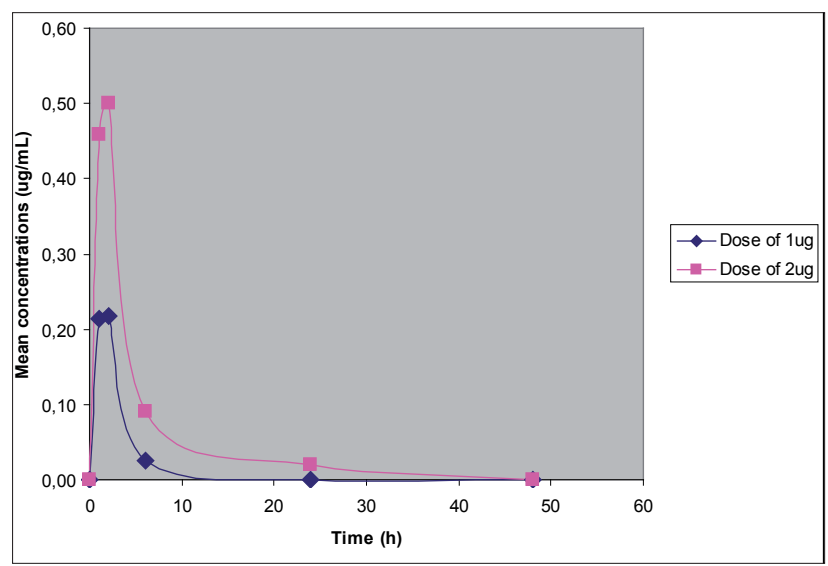

Fig. 4. Plasma levels of topotecan after after transcorneal intravitreal injection of $1 \mu \mathrm{g}(\downarrow)$ and after transcorneal intravitreal injection of $2 \mu \mathrm{g}(\mathbf{\square})$.

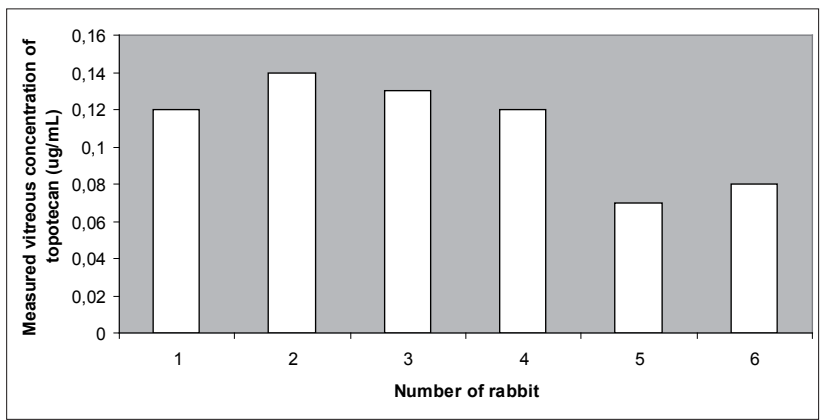

Fig. 5. Vitreous levels of topotecan in left eyes at $6 \mathrm{~h}$ after transcorneal intravitreal injection of $2 \mu \mathrm{g}(\boldsymbol{\square})$ in each rabbit. Only right eyes were injected. Symbols represent individual data points in each rabbit.

and b-wave amplitudes of right eyes. We observed no significant decrease in ERG activity of left eyes at the end of the experiment.

\section{DISCUSSION}

Recently, topotecan was demonstrated to have potent and rapid activity against human retinoblastoma in vitro ${ }^{20}$. Low calculated vitreous concentrations of $0.008-0.13 \mu \mathrm{g} /$ $\mathrm{mL}$ of topotecan were required to reduce Weri or Y79 retinoblastoma cell line viability by $50 \%$ within 15 min of exposure. Thus, we can report that in the present study, potentially cytotoxic concentrations were attained in the vitreous humor after the transcorneal intravitreal injection of both $1 \mu \mathrm{g}$ and $2 \mu \mathrm{g}$ of topotecan. These doses were five times and two times less than those injected in a previously published experiment ${ }^{18}$ but were sufficient to maintain potentially cytotoxic topotecan vitreous humor exposure for up to $6 \mathrm{~h}$. Nevertheless, the higher dose of topotecan delivered transcorneally intravitreally in this study did not significantly prolong exposure time to topotecan. After overcoming the hemato-ocular barrier using transcorneal 


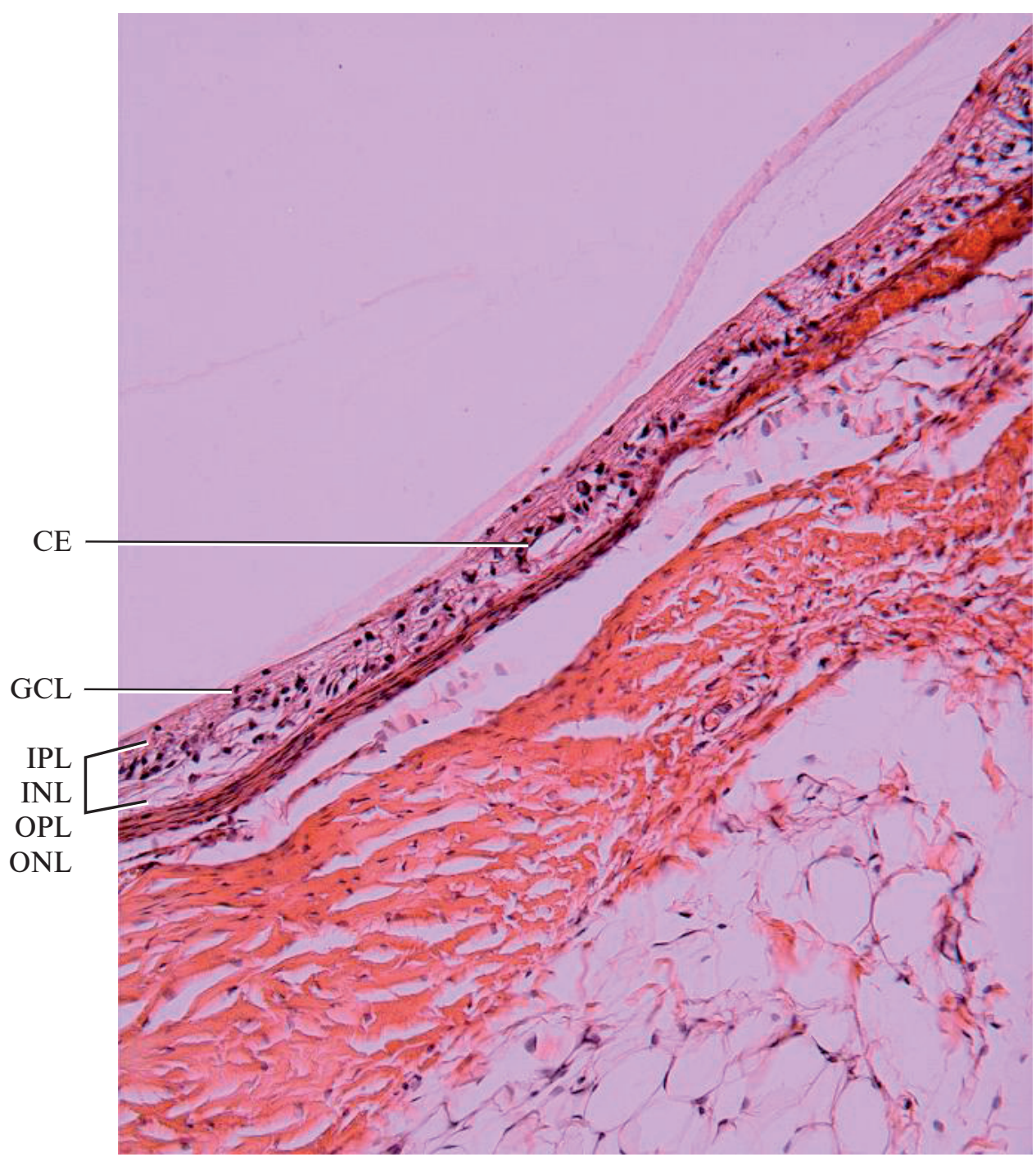

Fig. 6. Histologic section of retina stained with haematoxylin \& eosin. Reduction of ganglion cells in ganglion cell layer (GCL), choroidal edema (CE), inner plexiform layer (IPL), inner nuclear layer (INL), outer plexiform layer (OPL), outer nuclear layer (ONL). intravitreal injection, topotecan probably circulated along with the intraocular fluid flow and may have partially drained out of the eye via the trabecular meshwork. The results, measured in the anterior chamber after intravitreal delivery of $5 \mu \mathrm{g}$ of topotecan ${ }^{18}$, support this explanation.

Calculated topotecan vitreous concentrations were higher than measured concentrations for both groups equally. These differences may have been caused by irregular distribution of topotecan within the vitreous humor. Corresponding with the first published study ${ }^{18}$, using intravitreal topotecan injection, we also observed sufficient concentrations of topotecan in plasma. Contrary to carboplatin, a commonly used chemotherapeutic for retinoblastoma treatment, topotecan does not irreversibly bind local protein to produce inactive complexes that could lead to resistance of tumor cells and to chemotherapy failure $^{12}$. Low affinity to proteins could cause fast clearance of topotecan from the vitreous humor.

One interesting and unexpected finding is that relatively high topotecan vitreous concentrations were attained in untreated left eyes $6 \mathrm{~h}$ after the injection of $2 \mu \mathrm{g}$ of topotecan. As published previously ${ }^{15-18}$, topotecan can traverse the blood-retinal barrier into the vitreous humor or into the systemic circulation. In the present study, $2 \mu \mathrm{g}$ of topo- tecan reached sufficient concentrations in plasma and in the contralateral vitreous humor. Data from the untreated eyes after the intravitreal injection of $5 \mu \mathrm{g}$ of topotecan were not published in the study referred to above ${ }^{18}$. The transscleral approach used in this study ${ }^{18}$, could cause retinoblastoma intraorbital dissemination during drug intravitreal delivery in retinoblastoma patients. Therefore, we used a more difficult approach through the limbus, anterior chamber and peripheral iris. This process of intravitreal injection resulted in minimal bleeding and no retinal detachment even after repeated sampling.

To our knowledge, there is no previously reported information about topotecan side-effects when the drug is administred directly into the vitreous humor. Reduction of ganglion cells with focal retinal atrophy in 2 treated and 2 untreated eyes of group B were found as an adverse side effect of treatment. Consequently, the statistical analysis of electroretinograms displayed insignificant increase of a-wave and b-wave amplitudes of both eyes in group B. We should consider the high intraocular pressure and transient ischemia at the time of topotecan or saline administration that could contribute to this finding. These results are characteristic for initial stages of retinal degeneration after intoxication or hypoxia. Repeated sampling could 
lead to decrease in vitreous humor and its replacement by aqueous humor. Fluctuation in intraocular pressure could cause choroidal edema occurrence in most cases. Other observed findings such as corneal vascularization, cataractous changes, vitreous hemorrhage and eyelid inflammation may be the result of repeated mechanical irritation and incautious puncture.

\section{CONCLUSION}

Our findings proved that potentially cytotoxic topotecan concentrations were attained in the vitreous humor of the injected eyes after transcorneal intravitreal delivery. A twofold higher dose of topotecan did not prolong the exposure time to topotecan. Sufficient concentrations of topotecan were also measured in the plasma for both groups. These finding suggest the possibility of attaining potentially cytotoxic concentrations of topotecan in plasma after intravitreal delivery in children but we found no side-effects on the rabbit's body in this experiment. Focal retinal atrophy in 2 treated and 2 untreated eyes of the 6 rabbits was observed after intravitreal delivery of 2 $\mu \mathrm{g}$ of topotecan. Consequently, the ERGs displayed insignificant increase in a-wave and b-wave amplitudes of both eyes in group B. These findings may have been caused by retinal intoxication or hypoxia. No serious histopathological side-effects were noted after transcorneal intravitreal delivery of $1 \mu \mathrm{g}$ of topotecan. Nevertheless, other histopathological and functional studies are necessary.

\section{ACKNOWLEDGMENT}

To GlaxoSmithKline, England for topotecan donation. Supported by a grant of the Grant Agency of Charles University No. 63008.

\section{REFERENCES}

1. Baráková D. Retinoblastom. In: Baráková D, editor. Nádory oka. Praha: Grada; 2002. p.132-49.

2. Řehůřek J, Autrata R. Retinoblastom. In: ADAM, Z. $\neg$ VORLÍČEK J et al. Speciální onkologie. Brno: Masarykova univerzita v Brně; 2002. p.261-2.

3. Shields CL, Meadows AT, Leahey AM, Shields JA. Continuing challenges in the management of retinoblastoma with chemotherapy. Retina 2004;24:849-62.

4. Shields CL, Honavar SG, Meadows AT, Shields JA, Demirci H, Singh A, Friedman DL, Naduvilath TJ. Chemoreduction plus focal therapy for retinoblastoma: factors predictive of need for treatment with external beam radiotherapy or enucleation. Am J Ophthalmol 2002;133:657-64.
5. Abramson DH, Frank CM, Dunkel IJ. A phase I/II study of subconjunctival carboplatin for intraocular retinoblastoma. Ophthalmol 1999;106:1947-50.

6. Hayden BC, Jockovich ME, Murray TG, Voigt M, Milne P, Kralinger M, Feuer WJ, Hernandez E, Parel JM. Pharmacokinetics of Systemic Versus Focal Carboplatin Chemotherapy in the Rabbit Eye: Possible Implication in the Treatment of Retinoblastoma. Invest Ophthalmol Vis Sci 2004:45:3644-9.

7. Mendelsohn ME, Abramson DH, Madden T, Tong W, Tran HT, Dunkel IJ. Intraocular Concentrations of chemotherapeutic agents after systemic or local administration. Arch Ophthalmol. 1998;116:1209-12.

8. Pochop P, Darsova D, Kukacka J, Tesfaye H; Vajner L, Uhlik J, Kodetova D, Malis J, Dotrelova D. Intravitreal carboplatin concentration and area under concentration versus time curve after intravitreal and periocular delivery. Europ J Ophthalmol 2010;20:745-51.

9. Schmack I, Hubbard GB, Kang SJ, Aaberg TM, Grossniklaus HE. Ischemic necrosis and atrophy of the optic nerve after periocular carboplatin injection for intraocular retinoblastoma. Am J Ophthalmol 2006;142:310-15.

10. Abramson DH. Periocular chemotherapy for retinoblastoma: success with problems?. Arch Ophthalmol 2005;123:128-9.

11. Burris HA, Hanauske AR, Johnson RK, Marshall MH, Kuhn JG, Hilsenbeck SG, Von Hoff DD. Activity of topotecan, a new topoisomerase I inhibitor, against human tumor colony-forming units in vitro. J Natl Cancer Inst 1992;84:1816-20.

12. Slichenmyer WJ, Rowinsky EK, Donehower RC, Kaufmann SH. The current status of camptothecin analogues as antitumor agents. J Natl Cancer Inst 1993;85:271-91.

13. Santana VM, Zamboni WC, Kirstein MN, Tan M, Liu T, Gajjar A, Houghton PJ, Stewart CF. A pilot study of protracted topotecan dosing using a pharmacokinetically guided dosing approach in children with solid tumors. Clin Cancer Res 2003;9:633-40.

14. Furman WL, Stewart CF, Kirstein M, Kepner JL, Bernstein ML, Kung F, Vietti TJ, Steuber CP, Becton DL, Baruchel S, Pratt CH. Protracted intermittent schedule of topotecan in children with refractory acute leukemia: a pediatric oncology group study. J Clin Oncol 2002;20:1617-24.

15. Chantada GL, Fandiñ AC, Casak SJ, Mato G, Manzitti J, Schvartzman E. Activity of topotecan in retinoblastoma. Ophthalmic Genet 2004;25:37-43.

16. Carcaboso AM, Bramuglia GF, Chantada GL, Fandiño AC, Chiappetta DA, de Davila MTG, Rubio MC, Abramson DH. Topotecan vitreous levels after periocular or intravenous delivery in rabbits: an alternative for retinoblastoma chemotherapy. Invest Ophthalmol Vis Sci 2007;48:3761-7.

17. Tsui JY, Dalgard C, Van Quill KR, Lee L, Grossniklaus HE, Edelhauser HF, O'Brien JM. Subconjunctival topotecan in fibrin sealant in the treatment of transgenic murine retinoblastoma. Invest Ophthal Vis Sci 2008;49:490-6.

18. Buitrago $E$, Höcht $C H$, Fandiño $A C$, Navo $E$, Abramson DH, Schaiquevich P, Bramuglia G. Pharmacokinetic analysis of topotecan after intra-vitreal injection. Implications for retinoblastoma treatment. Exp Eye Res 2010;91:9-14.

19. Saravanan G, Suryanarayana MV, Balaji N, Someswararao N, Sekhar NM. A stability-Indicating LC method for assay of topotecan hydrochloride. Chromatogr 2008;67:179-82.

20. Laurie NA, Gray JK, Zhang J, Leggas M, Relling M, Egorin M, Stewart C, Dyer MA. Topotecan combination chemotherapy in two new rodent models of retinoblastoma. Clin Can Res 2005;11:7569-78.

21. Pardue MT, Hejny C, Gilbert JA, Philips MJ, Geroski DH, Edelhauser HF. Retinal function after subconjunctival injection of carboplatin in fibrin sealant. Retina 2004;24:776-82. 